\title{
Honeybee worker larvae perceive queen pheromones in their food
}

\author{
Michal Woyciechowski, Karolina KuszewsKa, Jędrzej PitoraK, Justyna KieRAT \\ Institute of Environmental Sciences, Jagiellonian University, Gronostajowa 7, 30-387, Kraków, Poland
}

Received 17 February 2016 - Revised 31 May 2016 - Accepted 22 June 2016

\begin{abstract}
Honeybee workers develop from fertilised eggs, but those reared in a queenless colony develop into 'rebel' workers, which are more queen-like than typical workers. Rebels develop after an old queen leaves with a swarm and before a new queen hatches. We hypothesised that larval food lacking queen mandibular pheromones trigger the rebel phenotype. Larvae reared under queenright or queenless conditions were additionally fed with water or a drop of macerated queen mandibular glands. After following development of the bees and subjecting them to dissection, we found that those reared with a queen or fed the macerated glands under queenless conditions developed into typical workers. Only those workers reared without a queen and without macerated glands added to their food developed into rebels; these rebels had more ovarioles, smaller hypopharyngeal glands, and larger mandibular and Dufour's glands than did typical workers. This is the first evidence that larval perception of the presence or absence of queen pheromones causes an alternative development strategy.
\end{abstract}

\section{Apis mellifera / honeybee / queen pheromones / queen recognition / rebel workers}

\section{INTRODUCTION}

Reproductive division of labour and the development of a non-reproductive worker caste are the most important features of eusocial insects and fundamental problems in evolutionary biology (Toth and Robinson 2007; Van Oystaeyen et al. 2014). A suite of traits likely evolves together with non-reproductive division of labour (Amdam et al. 2006; Wang et al. 2014), which is a key factor in the ecological success of eusocial insects (Wilson 1971). The best model for investigating these issues is the honeybee (Apis mellifera) colony, where queen mandibular pheromones (QMPs) play a crucial regulatory role in inhibiting ovarian development in adult workers and suppressing their reproduction (Van Oystaeyen et al. 2014). A large body of evidence indicates that queen pheromones

Corresponding author: M. Woyciechowski, michal.woyciechowski@uj.edu.pl Handling Editor: Stan Schneider also inform workers about the presence of the queen or her reproductive potential, which suggests that these pheromones have a signalling rather than control function (Woyciechowski and Lomnicki 1987; Tan et al. 2015). However, it is unknown whether QMPs communicate information only between queen and adult workers or are also instrumental in larval development. The latter possibility is of interest in view of the recent finding that worker larvae reared in a queenless colony develop into rebel workers, which are more queen-like than other workers (Woyciechowski and Kuszewska 2012). Compared with typical workers, the rebels have more ovarioles in the ovaries and less developed hypopharyngeal glands, which are used for brood food production, whereas their mandibular glands, which in queens produce QMPs, and Dufour's gland are larger (Kuszewska and Woyciechowski 2015). Rebel workers do not occur in honeybee colonies throughout the entire season but typically appear after swarming. Swarming is the one means by which colonies multiply in 
nature. After the mother queen leaves her colony with the swarm and before the new queen hatches, some larvae complete their feeding under queenless conditions and become rebels. Before swarming, the workers rear their own sisters and brothers, whereas after queen exchange, they are obligated to tend to their nieces and nephews. According to inclusive fitness theory (Hamilton 1964), the decrease in relatedness between the workers of the mother queen generation and the offspring of the new sister queen favours the rebel phenotype, as evidenced by workers that prioritise their own reproduction at the expense of rearing the offspring of the sister queen (Woyciechowski and Kuszewska 2012). There is another benefit from the enhanced reproductive potential of rebels. Quite often, the young queen that is replaced during swarming dies on her mating flight (Kraus et al. 2004; Schlüns et al. 2004). If this happens, rebels hatch in a hopelessly orphaned colony. The colony as a whole then only has one option: to produce a last batch of drones, for which rebel workers appear to be particularly effective. Rebel workers are easily produced in an artificially dequeened honeybee colony because the absence of the mother queen for even a short time period is unambiguous to the colony members and indicates an upcoming queen change and subsequent decrease in intracolony relatedness.

Honeybee queen signals are transferred via trophallaxis, i.e. the exchange of liquid food among colony members (Seeley 1979). These cues can change the feeding strategy of nurses towards larvae (Kuwabara 1948; Woyke 1999). However, we examined in this study whether cues indicating the presence or absence of a queen are detected from food by worker larvae directly and whether these larvae adjust their strategy accordingly, namely by developing into normal workers if QMPs are present in the food or into rebels if these pheromones are absent.

\section{MATERIALS AND METHODS}

Our experiments were performed in May and June of 2013 in the experimental apiary of the Institute of Environmental Sciences at Jagiellonian University in Poland. Before beginning our main experiments, we prepared a mixture containing queen pheromones. We dissected the mandibular glands from five alien, laying queens and macerated them in $3 \mathrm{~mL}$ of distilled water. The mixture was divided into Eppendorf tubes and frozen.

We used two colonies of honeybees (A. mellifera) that were treated in the same way. Initially, we restricted the queens to two frames. After $24 \mathrm{~h}$, we divided the colonies into queenright and queenless subunits, each containing one experimental frame with eggs of known age. When the larvae hatched on the experimental frames, we marked groups of 36 cells with larvae for the different treatments. Each queenright and queenless subunit contained two control groups of larvae: one that was not treated and one in which a drop of water was added to the food (watercontrol). In a third group, which was marked only in the de-queened subunit, we added a drop of macerated queen mandibular glands to the food of the larvae. The drop of water or liquid macerated gland mixture was added to the food near the larva bodies. Depending on larva age, we added different amounts of water or mandibular gland mixture: $0.5 \mu \mathrm{L}$ on the first 2 days, $1.0 \mu \mathrm{L}$ on the next 2 days, and $2.0 \mu \mathrm{L}$ on the last 2 days of larval feeding. We treated the larvae every $12 \mathrm{~h}$.

When all of the larvae in the experimental frames were capped, we moved the frames into an incubator and covered each experimental group of workers with a small plastic basket to separate the groups of bees from one another. This procedure caused some hatched bees to die before they were collected; therefore, only the surviving, freshly emerged workers were frozen and then dissected. We counted the number of ovarioles in both ovaries and measured the average sizes of the mandibular glands, Dufour's gland, and the acini in the hypopharyngeal glands of each worker with a stereomicroscope (Woyciechowski and Kuszewska 2012; Kuszewska and Woyciechowski 2015). The size of the mandibular gland was calculated as the average of the left and right glands (square root of longest $\times$ shortest diameters). The size of Dufour's gland was calculated as the square root of length $\times$ width. The size of the hypopharyngeal gland was calculated from the average of 10 acini (square root of longest $\times$ shortest diameters of five acini from the right gland and five from the left gland).

A mixed model two-way ANOVA was used to compare the parameters of workers (i.e. ovariole number, hypopharyngeal gland size, mandibular gland size, and Dufour's gland size) reared as larvae under different conditions. The experimental group was a fixed effect, and the colony was a random effect. If a difference among groups was statistically significant, the ANOVA was followed by multiple comparison testing using a post 
hoc Tukey HSD test with $P=0.05$ as the level of significance. All analyses were conducted using two-tailed statistical tests and were performed with STATISTICA 9.0.

\section{RESULTS AND DISCUSSION}

We compared the anatomical characters of freshly hatched workers that had developed from the different treatment groups of larvae. We found that in each of the colonies, the anatomical characters of the workers that had developed from the larvae with QMPs in their food, that is, those reared under the queenright condition and those reared in the queenless subunits that had macerated queen mandibular glands added to their food, did not differ from each other (Figure 1). Only one difference with regard to hypopharyngeal gland size was observed in the latter colony. By analysing the data from the two colonies together, we found that the characters of all the workers that had contact with QMPs differed from the workers reared in the queenless subunits in which the larvae had no contact with QMPs. These latter workers had traits typical of rebels, making them more queen-like. The rebels had more ovarioles in their ovaries (factorial twoway ANOVA, $\left.F_{4,4}=176.3 ; P<0.001\right)$ and larger mandibular (factorial two-way ANOVA, $F_{4,4}=$ 19.5; $P=0.007$ ) and Dufour's glands (factorial two-way ANOVA, $F_{4,4}=45.7 ; P=0.001$ ) relative to the workers reared in contact with QMPs. In contrast, the acini of the rebels' hypopharyngeal glands were smaller than those of the workers exposed to QMPs (factorial two-way ANOVA, $F_{4,4}=$ 60.65; $P<0.001$ ) (Figure 1).

It has been suggested that the presence or absence of a queen is perceived not only by adult workers (Hoover et al. 2003; Peters et al. 2010) but also by the larvae of honeybees (Kocher et al. 2010; Woyciechowski and Kuszewska 2012) and bumblebees (Cnaani et al. 2000). However, in the present study, we show that queen pheromones, which are transmitted via trophallaxis, pass information to larvae, which can then change their developmental strategy. Despite the fact that the presented scenario is the most probable, we realise that alternative explanations are possible and that some unanswered questions remain. One such question is whether QMPs play a signalling role that is independent of their quantity in larval food. Indeed, in a queenright honeybee colony, it is unlikely that each larva obtains the same quantity of QMPs. Therefore, the amount of macerated gland added to the larval food under the queenless condition was not crucial to the results and, in particular, was not harmful to the larvae. The fact that the workers reared on this diet were anatomically similar to the workers hatched in the queenright colonies is in accordance with our suggestion. Another question worth discussing is whether nursing workers manipulate larval development when they detect QMPs in their food. Conversely, it is possible that larvae manipulate the behaviour of nursing workers, which has been observed in ants but not yet reported in bees (Creemers et al. 2003; Kaptein et al. 2005), except for Apis mellifera capensis larvae in a host colony of Apis mellifera scutellata (Beekman et al. 2000). It is difficult to predict the special adaptations that may be adopted by adult workers or larvae to a situation that never occurs under natural conditions, e.g. the presence of QMPs in larval food in a queenless colony. In such, a situation possible is that workers and/or larvae exhibit unpredictable reactions, but these were not observed during our experiment. To date, understanding of the rebel worker strategy in honeybees has primarily relied on assessments of the anatomical characters of rebel bees (Woyciechowski and Kuszewska 2012; Kuszewska and Woyciechowski 2015). We expect that the larger ovaries and smaller hypopharyngeal glands of rebels are associated with reductions in engagement in tasks important for colony maintenance, which is concordant with previous observations (Mattila et al. 2012, but see also Naeger et al. 2013). Furthermore, it remains unknown whether the presence of rebel workers affects the production of males and their chances of mating. Worker reproduction is seasonally influenced, and sons of rebels usually follow peak swarming times to meet virgin queens ready for mating (Holmes et al. 2013). However, the fact that rebels are more queen-like because their mandibular and Dufour's glands are larger than those in other workers suggests that their eggs escape policing (Miller and Ratnieks 2001), meaning that they are not eaten by other workers. If this is true, the personal fitness of rebels could explain their alternative developmental strategy at the larval stage. 
a

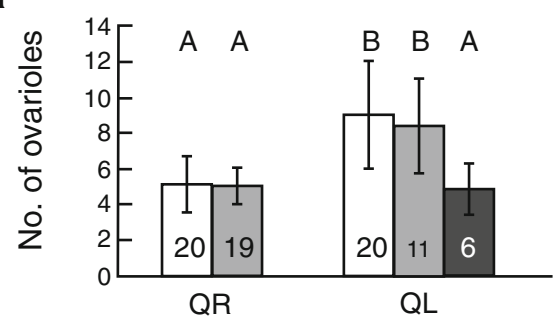

b

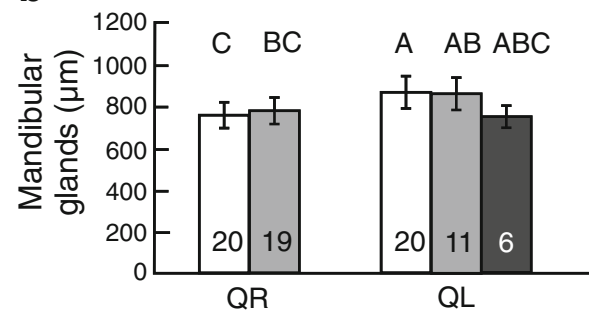

C
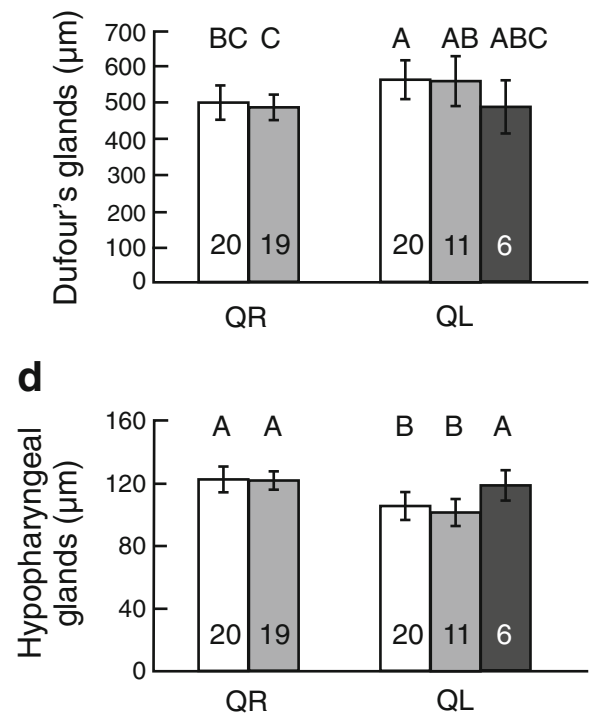

Colony 2

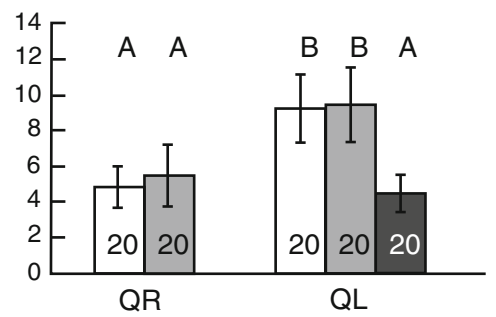

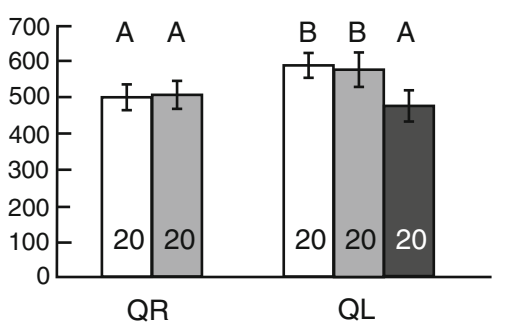

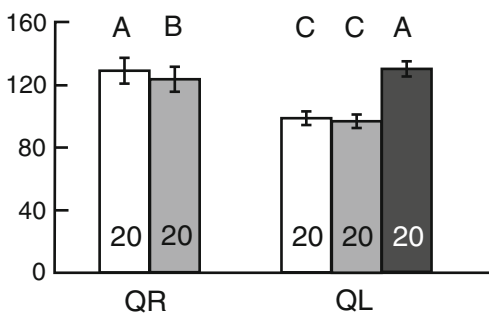

Figure 1. Anatomical characters (mean $\pm \mathrm{SD}$ ) of newly emerged honeybee workers reared as larvae in two colonies divided into queenright subunits (QR) and queenless subunits (QL). Data for control workers (open bars ), workers fed as larvae with water drops (light-shadowed bars), and workers fed as larvae with macerated queen mandibular glands (dark-shadowed bars) are shown. The numbers in the bars represent the numbers of tested workers. Bars with the same letters above them did not exhibit significant differences between averages within the same colony, and bars with different letters above them exhibited statistical differences at the $P<0.05$ level (multiple comparison testing using a post hoc Tukey HSD test for interaction colony $\times$ treatment). a Number of ovarioles. b Size of mandibular glands. c Size of Dufour's glands. d Size of hypopharyngeal glands. For additional details, see Section 2.

In summary, we confirmed that the worker caste in honeybees has two discrete subcastes that are formed depending on whether worker larvae develop under queenless or queenright conditions.
This phenomenon makes this species an even more attractive model than previously supposed for both epigenetic studies (Amdam et al. 2004; Elango et al. 2009; Drewell et al. 2012) and intragenomic 
conflict studies investigating whether worker reproduction is more heavily promoted by patrigenes than matrigenes (Queller 2003; Galbraith et al. 2016). It is possible that the queen disseminates her pheromones to block the development of worker ovaries and the growth of mandibular and Dufour's glands simultaneously, thereby encouraging the development of hypopharyngeal glands; however, we suggest that the presence or absence of QMPs acts as a signal to which larvae respond. If this is true, we believe that our study provides the first evidence in eusocial insects that larval perception of the presence or absence of queen pheromones induces an alternative development strategy.

\section{ACKNOWLEDGMENTS}

We thank the editor and anonymous reviewers for their suggestions and comments on our manuscript. We also thank the editorial service American Journal Experts for improving the language usage in our manuscript. Jagiellonian University grant DS/BiNoZ/INoS/ 761/13-16, the Polish Ministry of Science and Higher Education grant Iuventus Plus IP2012 026072, and the European Commission under grant 244090-STEP-CPFP (Status and Trends of European Pollinators; www.step-project.net) within the European Union Seventh Framework Programme supported this work.

\section{OPEN ACCESS}

This article is distributed under the terms of the Creative Commons Attribution 4.0 International License (http://creativecommons.org/licenses/by/4.0/), which permits unrestricted use, distribution, and reproduction in any medium, provided you give appropriate credit to the original author(s) and the source, provide a link to the Creative Commons license, and indicate if changes were made.

Les larves d'ouvrières d'abeille perçoivent les phéromones de la reine dans leur nourriture

Apis mellifera / phéromones de la reine / reconnaissance de la reine / ouvrières 'anarchistes'

Arbeiterinnenlarven der Honigbiene erkennen Pheromone der Königin in ihrem Futter

Apis mellifera / Honigbiene / Königinnenpheromon / Königinnenerkennung / Anarchistische Arbeiterinnen

\section{REFERENCES}

Amdam, G.V., Norberg, K., Fondrk, H.K., Page Jr., R.E. (2004) Reproductive Ground Plan may mediate colony-level selection effects on individual foraging behavior in honey bees. Proc. Natl. Acad. Sci. U. S. A. $101(31), 11350-11355$

Amdam, G.V., Csondes, A., Fondrk, M.K., Page, R.E. (2006) Complex social behaviour derived from maternal reproductive traits. Nature 439 (7072), 76-78

Beekman, M., Calis, J.N.M., Boot, W.J. (2000) Parasitic honeybee get royal treatment. Nature 404 (6779), 723

Cnaani, J., Robinson, G.E., Bloch, G., Borst, D., Hefetz, A. (2000) The effect of queen-worker conflict on caste determination in the bumblebee Bombus terrestris . Behav. Ecol. Sociobiol. 47 (5), 346-52

Creemers, B., Billen, J., Gobin, B. (2003) Larval begging behaviour in the ant Myrmica rubra. Ecol. Evol. 15 (3), 261-272

Drewell, R.A., Lo, N., Oxley, P.R., Oldroyd, B.P. (2012) Kin conflict in insect societies: a new epigenetic perspective. Trends Ecol. Evol. 27 (7), 367-373

Elango, N., Hunt, B.G., Goodisman, M.A.D., Soojin, V.Y. (2009) DNA methylation is widespread and associated with differential gene expression in castes of the honeybee, Apis mellifera. Proc. Natl. Acad. Sci. U. S. A. 106 (27), 11206-11211

Galbraith, D.A., Kocher, S.D., Glenn, T., Albert, I., Hunt, G.J., Strassmann, J.E., Queller, D.C., Grozinger, C.M. (2016) Testing the kinship theory of intragenomic conflict in honey bee (Apis mellifera). Proc. Natl. Acad. Sci. U. S. A. 113 (4), 1020-1025

Hamilton, W.D. (1964) The genetical evolution of social behaviour I-II. J. Theor. Biol. 7, 1-54

Holmes, M.J., Oldroyd, B.P., Duncan, M., Allsopp, M.H., Beekman, M. (2013) Cheaters sometimes prosper: targeted worker reproduction in honeybee (Apis mellifera) colonies during swarming. Mol. Ecol. 22 (16), 4298-4306

Hoover, S.E., Keeling, C.I., Winston, M.L., Slessor, K.N. (2003) The effect of queen pheromones on worker honey bee ovary development. Naturwissenschaften 90 (10), 477-480

Kaptein, N., Billen, J., Gobin, B. (2005) Larval begging for food enhances reproductive options in the ponerine ant Gnamptogenys striatula . Anim. Behav. 69 (2), 293-299

Kocher, S.D., Ayroles, J.F., Stone, E.A., Grozinger, C.M. (2010) Individual Variation in Pheromone Response Correlates With Reproductive Traits and Brain Gene Expression in Worker Honey Bees. PLoS ONE 5 (2), e9116

Kraus, F.B., Neumann, P., Van Praagh, J., Moritz, R.F.A. (2004) Sperm limitation and the evolution of extreme polyandry in honeybees (Apis mellifera L.). Behav. Ecol. Sociobiol. 55(5), 494-501

Kuszewska, K., Woyciechowski, M. (2015) Age at which larvae are orphaned determines their development into typical or rebel workers in the honeybee (Apis mellifera L.). PLoS ONE 10 (4), e0123404 
Kuwabara, M. (1948) Über Die Regulation in weislossen wolke der Honigbiene (Apis mellifica) besonders die Bestimmung des neuen Weisels. J. Fac. Sci. Hokkaido Univ. Ser. VI. 9, 359-381

Mattila, H.R., Reeve, H.K., Smith, M.L. (2012) Promiscuous honey bee queens increase colony productivity by suppressing worker selfishness. Curr. Biol. 22 (21), 2027-2031

Miller, D.G., Ratnieks, F.L.W. (2001) The timing of worker reproduction and breakdown of policing behaviour in queenless honey bee (Apis mellifera L.) Societies. Insectes Soc. 48 (2), 178-184

Naeger, N.L., Peso, M., Even, N., Barron, A.B., Robinson, G.E. (2013) Altruistic behavior by egg-laying worker honeybees. Curr. Biol. 23 (16), 1574-1578

Peters, L., Zhu-Salzman, K., Pankiw, T. (2010) Effect of primer pheromones and pollen diet on the food producing glands of worker honey bees (Apis mellifera L.). J. Insect Physiol. 56 (2), 132-137

Queller, D.C. (2003) Theory of genomic imprinting conflict in social insects. BMC Evol. Biol. 3, 15

Schlüns, H., Koeniger, G., Koeniger, N., Moritz, R.F.A. (2004) Sperm utilization pattern in the honeybee (Apis mellifera ). Behav. Ecol. Sociobiol. 56 (5), 458-463

Seeley, T.D. (1979) Queen substance dispersal by messenger workers in honeybee colonies. Behav. Ecol. Sociobiol. 5 (4), 391-415
Tan, K., Liu, X., Dong, S., Wang, C., Oldroyd, B.P. (2015) Pheromones affecting ovary activation and ovariole loss in the Asian honey bee Apis cerana. J. Insect Physiol. 74, 25-29

Toth, A.L., Robinson, G.E. (2007) Evo-devo and the evolution of social behavior. Trends Genet. 23 (7), 334-341

Van Oystaeyen, A., Oliveira, R.C., Holman, L., van Zweden, J.S., Romero, C., Oi, C.A., d'Ettorre, P., Khalesi, M., Billen, J., Wäckers, F., Millar, J.G. (2014) Conserved class of queen pheromones stops social insect workers from reproducing. Science 343 (6168), 287-290

Wang, Y., Kaftanoglu, O., Fondrk, M.K., Page Jr., R.E. (2014) Nurse bee behaviour manipulates worker honeybee (Apis mellifera L.) reproductive development. Anim. Behav. 92, 253-261

Wilson, E.O. (1971) The Insect Societies. Belknap, Cambridge

Woyciechowski, M., Kuszewska, K. (2012) Swarming generates rebel workers in honeybees. Curr. Biol. 22 (8), 707-711

Woyciechowski, M., Lomnicki, A. (1987) Multiple mating of queens and the sterility of workers among eusocial hymenoptera. J. Theor. Biol. 128(3), 317-27

Woyke, J. (1999) Increased food supply to all larvae after dequeening honey bee colonies. J. Apic. Res. 38 (3-4), 117-123 